\title{
Redescription OF the MAle OF IXodes festal Rondelli, 1926 (IXOdidA: IXOdidAe) ON SPECIMENS FROM SARDINIA (ITALY)
}

\author{
CONTINI C.*, PALMAS C.*, SEU V.*, STANCAMPIANO L.** \& USAI F.**
}

\section{Summary:}

Ixodes festai Rondelli, 1926 is a poorly known bird parasite tick. Its immature forms have not been described yet, while the adult forms only insufficiently, especially the male. In this note the presence of the male of Ixodes festai for the first time in Sardinia (Italy) is reported and a detailed redescription is provided. Morphometric data as well as photographs performed both with optical and electron microscope (ESEM FEI Quanta 200) are also shown.

KEY WORDS: Ixodidae, Ixodes festai, description, male, Sardinia.
Résumé : REDESCRIPTION DU MÂLE DE IXODES FESTAI RONDELLI, 1926 (IXODIDA : IXODIDAE) SUR DES SPÉCIMENS DE SARDAIGNe (ITALIE) Ixodes festai Rondelli, 1926 est une espèce mal connue, parasite des oiseaux. Les stades immatures sont toujours actuellement non décrits, et les stades adultes eux-mêmes restent encore très partiellement décrits, notamment le mâle. Dans cet article, les auteurs décrivent le mâle de l'Ixodidae Ixodes festai signalé pour la première fois en Sardaigne (Italie), et une nouvelle description détaillée est fournie. En outre, des données morphométriques et des photographies prises par un microscope optique et par un microscope électronique ESEM FEI Quanta 200 complètent cet article.

MOTS-CLÉS : Ixodidae, Ixodes festai, description, mâle, Sardaigne.

(including Corsica) (Pérez-Eid, 2007). Its presence has also been recorded in Poland (Siuda et al., 1991; Siuda et al., 2006) and in Switzerland (Papadopulos et al., 2001).

Collected samples have always been few in number, confirming the rarity of the species. The male of $I$. festai remained moreover unknown until 2007, when Pérez-Eid described the male among specimens collected by Gilot in Bormes-les-Mimosas, Var, France (Pérez-Eid, 2007).

The presence in Italy of $I$. festai was reported for the first time by Contini (1998) who collected 24 individuals, all females, parasitizing mainly Turdus philomelos but also Turdus merula (Turdidae). The sampling was performed in the countryside of the Teulada and Capoterra municipalities (Cagliari province, Sardinia). More recently Iori et al. (2004) reported the presence of $I$. festai in two Italian islands, Ventotene (Latina province, Lazio) and Montecristo (Livorno province, Tuscany), examining two unidentified ingorged females collected by Manilla in 1990 on Turdus torquatus and T. philomelos (Turdiadae). This record, which the authors stated to be the first in Italy, did not take into account the previous report of Contini (1998).

To date, I. festai remains a poorly known species. Its immature forms have not been described yet, while the adult forms only insufficiently. In particular the male has only been barely described by Pérez-Eid (2007). The description given by this latter, indeed,

* Dipartimento di Scienze della Vita e dell'Ambiente, Macrosezione Biomedica, Università di Cagliari, Italy.

** Dipartimento di Scienze Mediche Veterinarie, Università di Bologna, Italy.

Correspondence: Carlo Contini, Dipartimento di Scienze della Vita e dell'Ambiente, Macrosezione Biomedica, Cittadella Universitaria, SS 554 bivio per Sestu, 09042 Monserrato, Cagliari, Italy.

E-mail: concarlo@tiscali.it 


\section{Dimensions (mm) or ratio}

\begin{tabular}{|c|c|c|c|c|}
\hline & Measure $\mathbf{N}$ & Mean & Min & $\operatorname{Max}$ \\
\hline Length of idiosome along the median longitudinal axis & 1 & 1.3 & 1.2 & 1.4 \\
\hline Max width at peritremes & 2 & 0.9 & 0.9 & 0.9 \\
\hline Length of scutum along the median longitudinal axis & 3 & 1.2 & 1.2 & 1.3 \\
\hline Max width of dorsal scutum & 4 & 0.7 & 0.7 & 0.7 \\
\hline Distance between scapulae & 5 & 0.3 & 0.3 & 0.3 \\
\hline Max length of basis capituli along the median longitudinal axis & 6 & 0.2 & 0.2 & 0.2 \\
\hline Max length of basis capituli at cornua & 7 & 0.2 & 0.2 & 0.2 \\
\hline Distance between cornua & 8 & 0.2 & 0.2 & 0.2 \\
\hline Max length of hypostome & 9 & 0.2 & 0.2 & 0.2 \\
\hline Max width of hypostome & 10 & 0.1 & 0.1 & 0.1 \\
\hline Max length of palp segment II along the median axis & 11 & 0.1 & 0.1 & 0.1 \\
\hline Max length of palp article III along the median axis & 12 & 0.2 & 0.1 & 0.2 \\
\hline Max width of palps & 13 & 0.1 & 0.1 & 0.1 \\
\hline Ratio of width of palp to length of its II segment & & $1: 1$ & 1:0.9 & $1: 1.1$ \\
\hline Ratio of width of palp to length of its III segment & & $1: 1.2$ & $1: 1.2$ & $1: 1.2$ \\
\hline Length of tarsus I & 16 & 0.4 & 0.4 & 0.4 \\
\hline Width of tarsus I & 17 & 0.1 & 0.1 & 0.1 \\
\hline Width to length ratio of tarsus I & & $1: 3.7$ & $1: 3.5$ & $1: 4.1$ \\
\hline Longitudinal diameter of ring of anal valve & 19 & 0.1 & 0.1 & 0.1 \\
\hline Longitudinal diameter of peritreme & 20 & 0.2 & 0.2 & 0.2 \\
\hline
\end{tabular}

Table I. - Morphometric data of male of Ixodes festai (4 specimens measured).
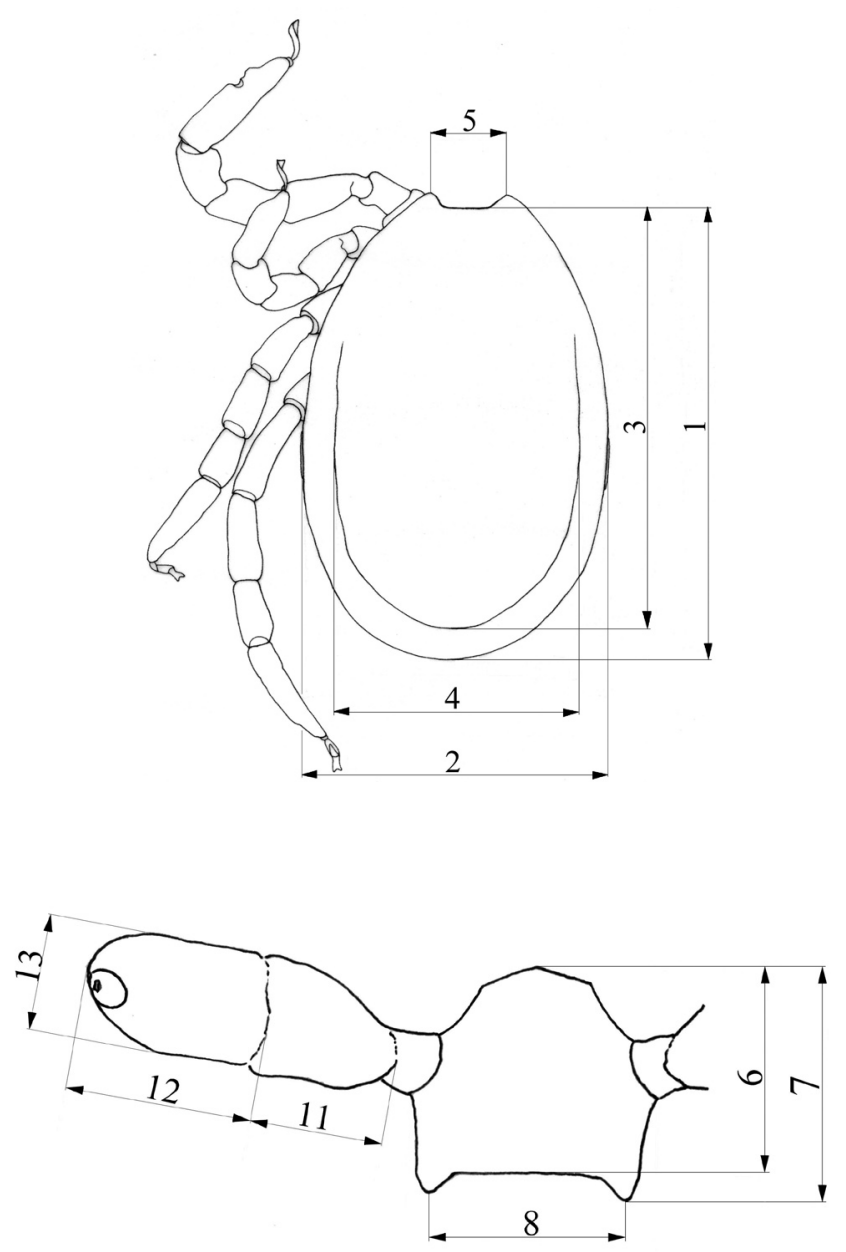
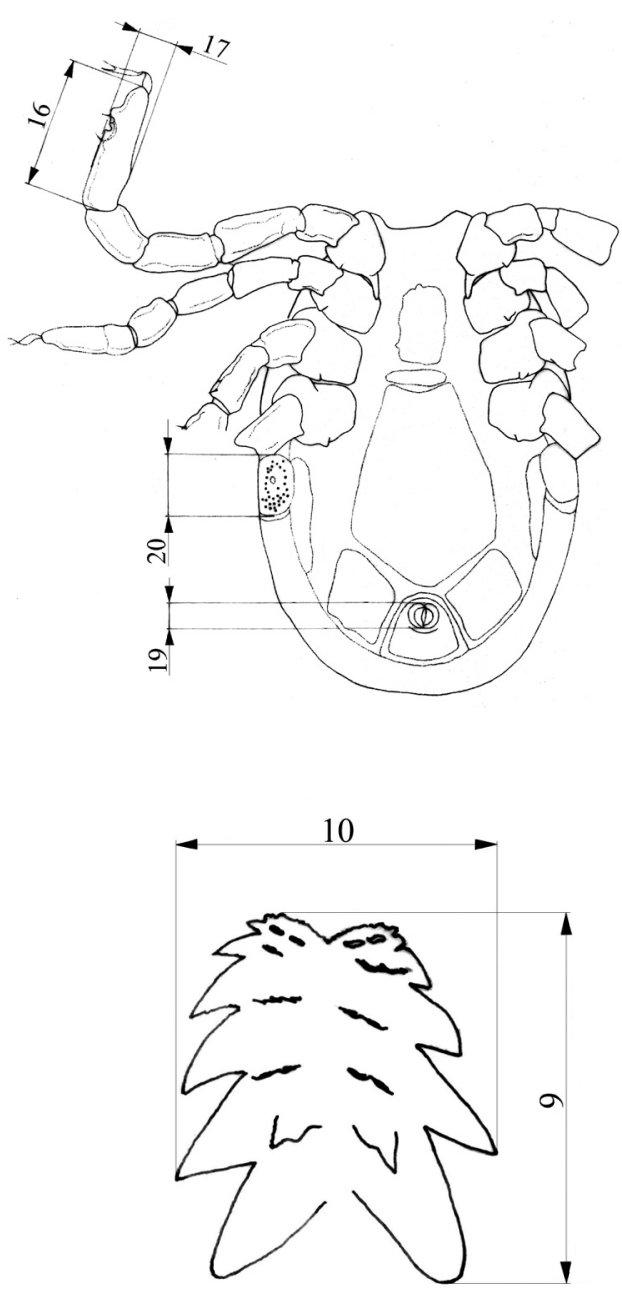
is very brief, the drawings are very schematic and photographs of the various anatomical details are not present.

In addition the male of $I$. festai has never been reported in Sardinia (Italy) before. In this paper we provide a detailed description of the male of I. festai, thus deepening the one given by Pérez-Eid (2007).

\section{MATERIALS AND METHODS}

F ollowing the publication of Contini (1998), we organized a second research in February 2000, always in the same locations, which allowed the capture of over one hundred specimens of I. festai, all of them collected from $T$. philomelos and $T$. merula.

Examining the collected material, five males and five females in copula were detected, as well as a free male lying on the abdomen of a female. I. festai specimens were mainly associated with T.philomelos in rural areas of the municipalities of Teulada (Monte Perdosu, Monte Nappa and Monte Sebera, Cagliari province) and Capoterra (San Gregorio and Poggio dei Pini, Cagliari province).

The specimens were first treated in heated $10 \% \mathrm{KOH}$ solution for 20 minutes, washed several times in a mild solution of acetic acid and distilled water, then in distilled water only and finally mounted in Faure's liquid. The morphological characters were studied in the five males in copula. The morphometric data are presented in Table I, where minimum, average and maximum values are expressed in millimeters. Measures were taken with a micrometer slide.

SEM photographs were performed on specimens stored in $70 \%$ ethanol solution, using the ESEM FEI Quanta 200 microscope.

\section{DESCRIPTION OF THE MALE OF I. FESTAI}

$\mathrm{B}$ ody very small, average length $1.7 \mathrm{~mm}$ (Table I, Figs 1, 3), of oval form, uniformly brown coloured, feet included. Dorsal shield covered with white rare bristles not uniformly distributed, absent in two small anterolateral areas, just below the scapulae (Figs 1, 2). Punctuations of a single type, large, distributed mainly in the posterior two thirds of the shield (Fig. 2). Lateral grooves deep and continuous, interrupted near the scapular areas. Cervical grooves very little marked (Fig. 2). Basis capituli plate (Fig. 2), roughly as long as wide in the length and width; posterior margin almost straight and with two robust triangular cornuae with rounded apex.
Dorsal surface of the basis capituli with 12-13 punctuations. The ventral surface is equipped with seven shields (Fig. 3) not very dissimilar in form and disposition from those of other species of Ixodinae. Coxae (Fig. 4) with long bristles. Coxa I (Fig. 5) provided with robust internal spur, straight, blunt, long about twice the width of the base and slightly placed on the coxa II; coxae I-IV (Figs 4-6) bearing external thorns whose ends are provided of 1-3 small cusps; coxa IV with, occasionally, a second rudimentary external thorn (Fig. 6); anterior tarsi as in Fig. 7. Spiracles rounded, just smaller than coxae IV (Fig. 3).

Hypostome (Fig. 8) short, provided with small teeth, with apex hollow V-shaped. Six sharp teeth are also present on each side which increase progressively in size from apex to base. The median region includes five rows on each side of rudimentary teeth similar to small crenations. The first row of teeth, just below the apex, consists of ovoidal elements.

\section{DISCUSSION}

T The new samples gathered in Sardinia are interesting as they provide further information. In particular they confirm the persistency of $I$. festa $i$ within the same biotope, as remarked by Contini (1998), which is an interesting aspect for migratory bird parasites. Furthermore this report considerably enlarge the amount of known samples, and does not confirm the conclusion drawn by Pérez-Eid regarding the sporadicity of this species on the basis of the small number of individuals in most collections.

The samples also confirm Turdus sp. as key host species in particular in Italy, which is an important aspect for the biology of this ectoparasites until now only rarely detected.

Below, we provide the main morphological characters useful for differentiating the male of $I$. festai from other Italian Ixodinae.

According to Manilla (1998) the Italian fauna of the genus Ixodes Latreille includes the following four species: I. ricinus (Linnaeus, 1758), I. gibbosus Nuttal, 1916, I. acuminatus Neumann, 1901 and I. ventalloi Gil Collado, 1936. Males of I. festai are separable from males of these species using the following diagnostic characters:

- cornuae present in I. festai, I. ventalloi and I. acuminatus, absent in I. ricinus and I. gibbosus;

- auriculae strongly reduced in I. festai and I. ventalloi, absent in I. acuminatus, present and forming a right angle in $I$. ricinus.

- internal thorn of the coxa I robust, straight and blunted in I. festai, pointed and arcuated in I. ventalloi; 
- tarsus I long and slender in I. festai, shorter, wider with untapered end in I. ventalloi;

- basis capituli with margins subparallel dorsally in $I$. festai, significantly divergent anteriorly in I. acuminatus; - internal thorns of the coxae II and III rudimentary in I. festai, more evident in I. acuminatus.

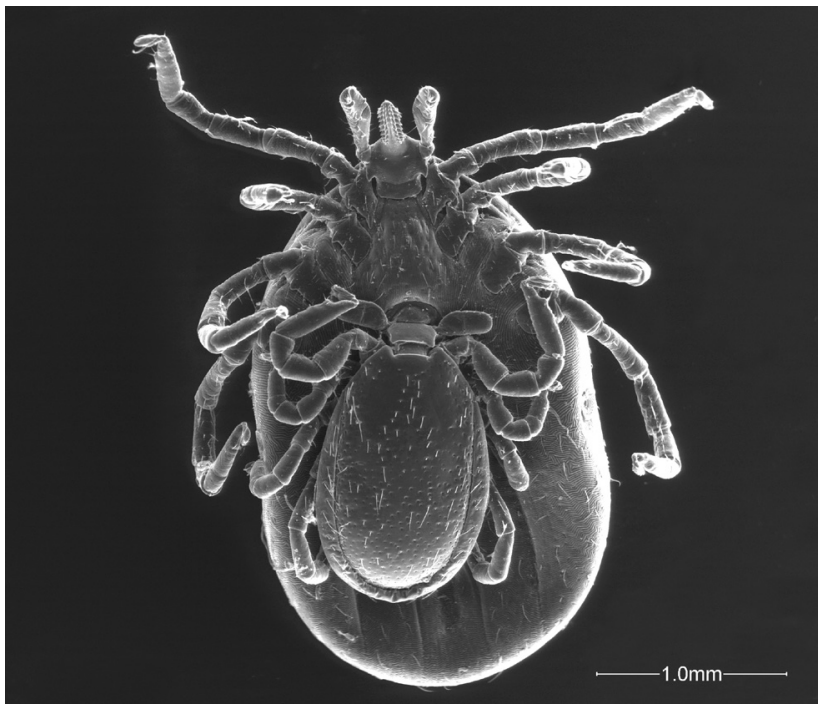

Fig. 1. - Male and female of Ixodes festai mating.

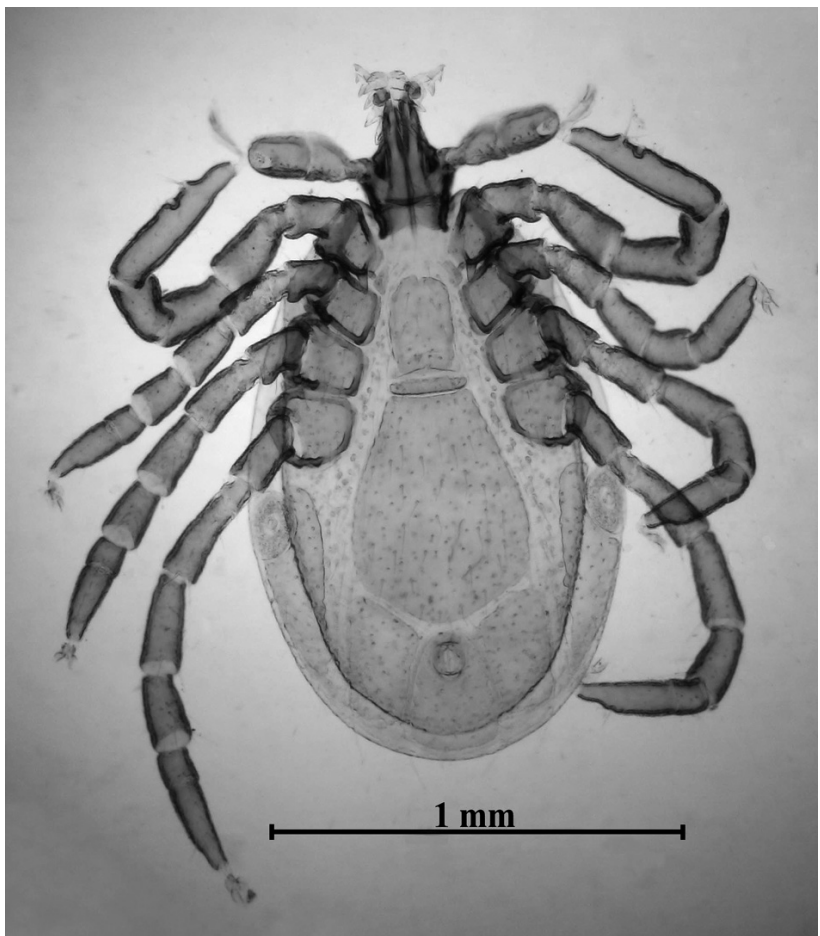

Fig. 3. - Male of Ixodes festai clarified in $\mathrm{KOH} 10 \%$ solution and mounted in Faure's liquid, lying dorsally.
In conclusion, this work besides providing a detailed description of the male of $I$. festai, adds new information regarding the distribution of this species. Further considerations about the reasons for such a strong presence of $I$. festai in Sardinia, would need to be deepened by further research.

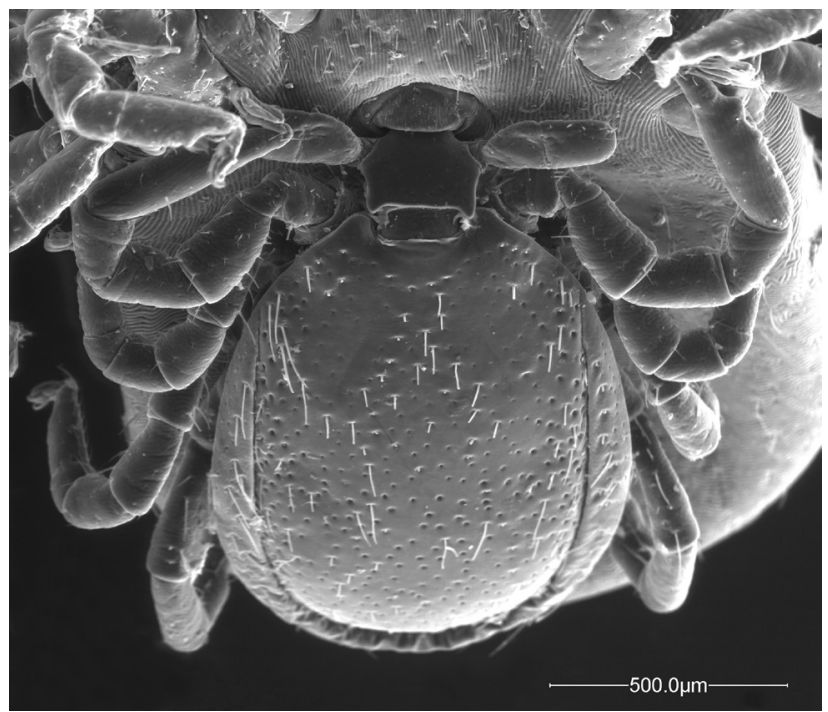

Fig. 2. - Particular of the male in figure 1.

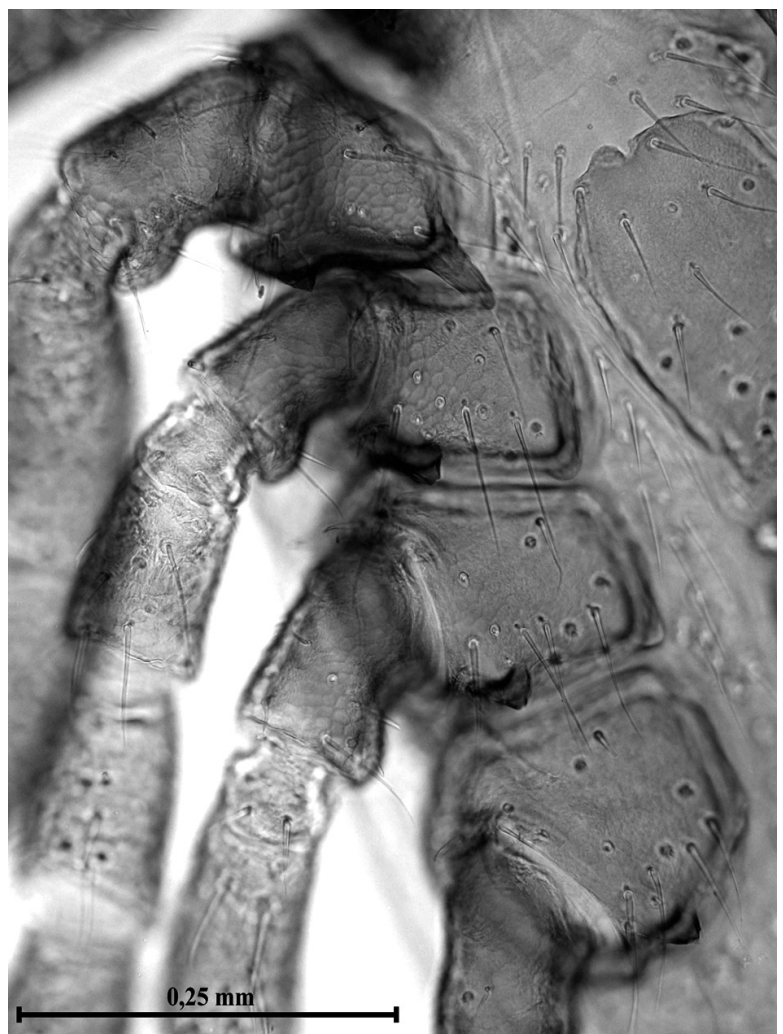

Fig. 4. - Coxae I-IV of the male of Ixodes festai. 


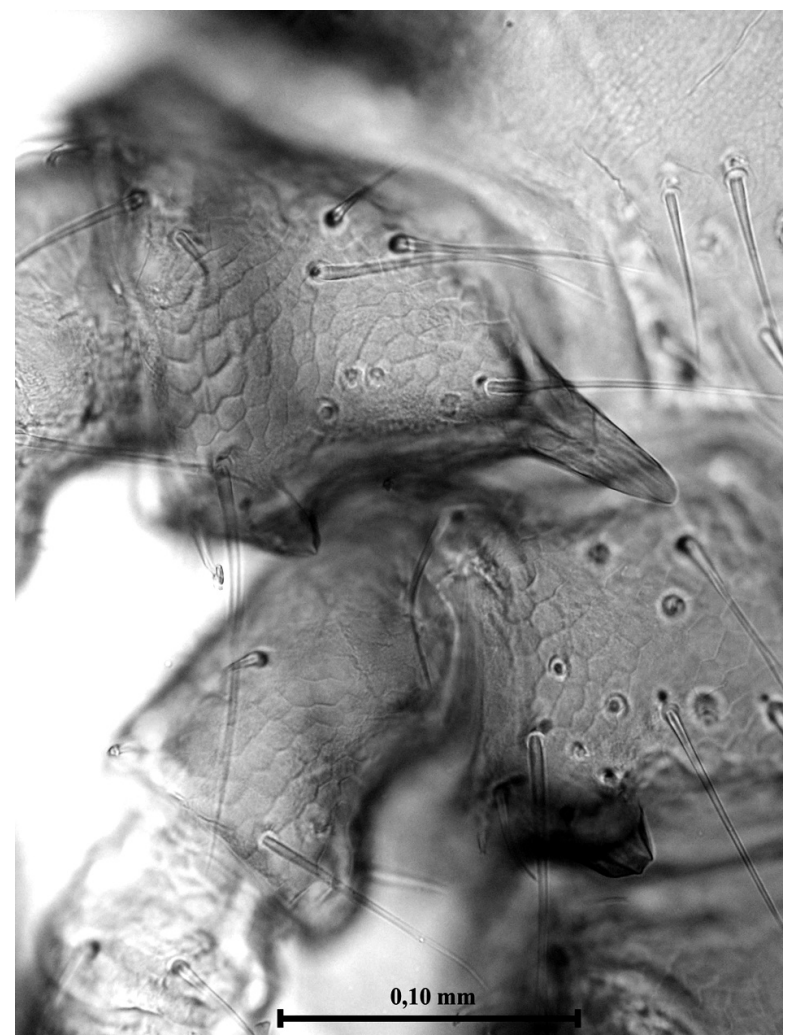

Fig. 5. - Particular of figure 4: internal and external thorn of the coxa I and external thorn of the coxa II of the male of Ixodes festai. The terminal cusps of the external thorns are well visible.

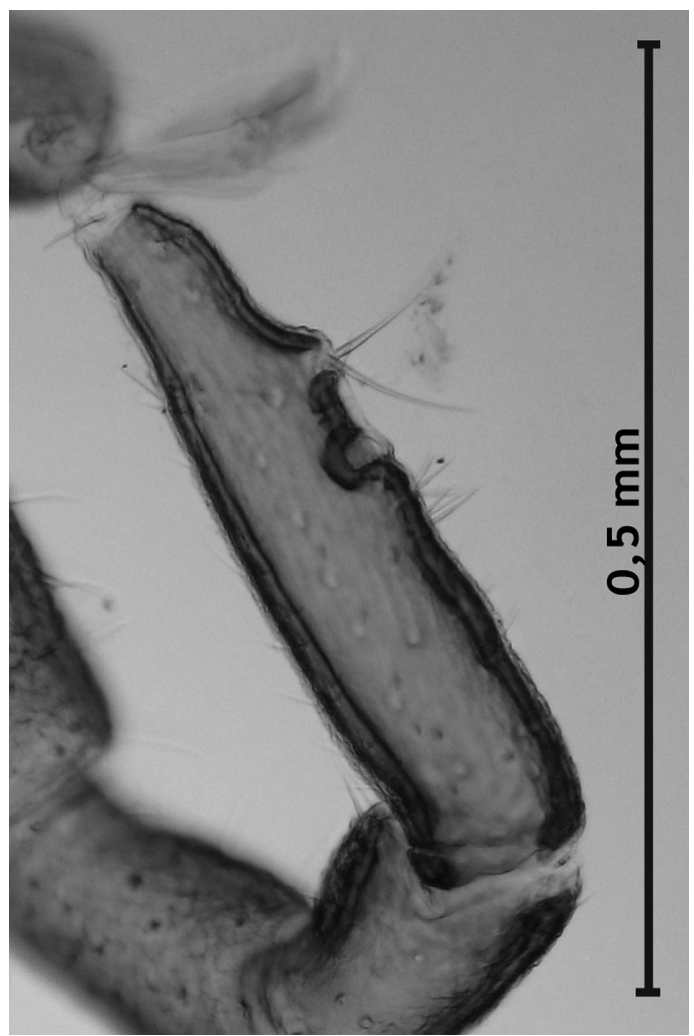

Fig. 7. - Tarsus of the leg I.

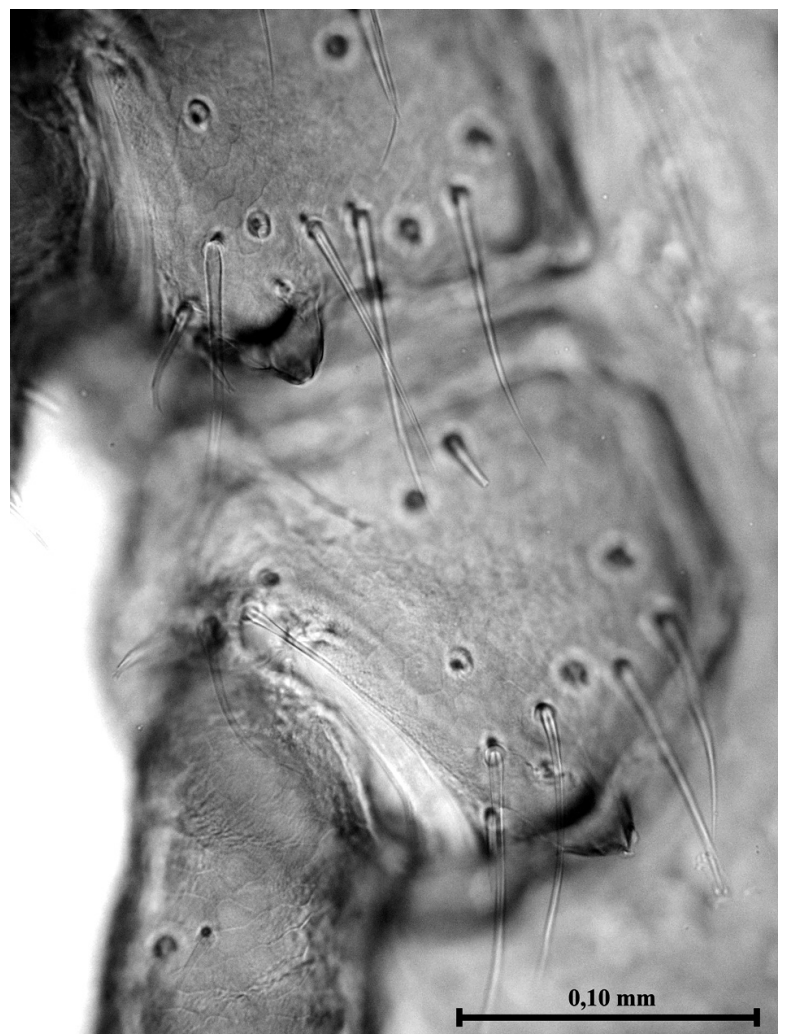

Fig. 6. - Particular of figure 4: external thorns of the coxae III and IV of the male of Ixodes festai. The terminal cusps of the external thorns are well visible.

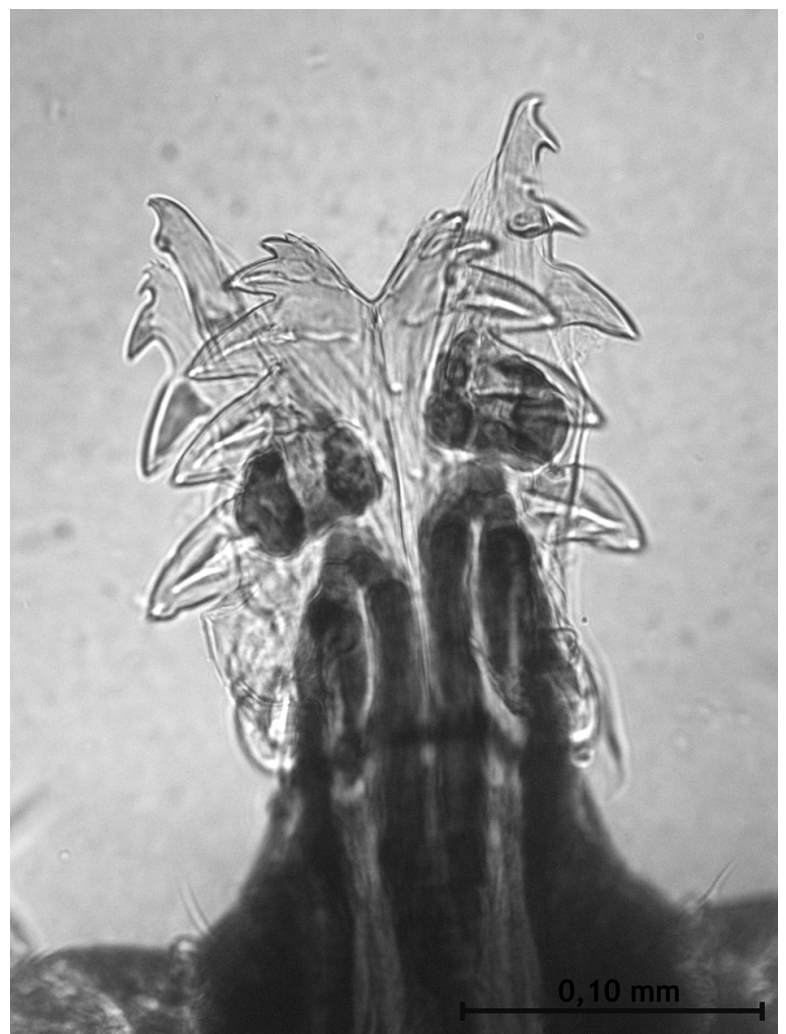

Fig. 8. - Hypostome of the male of Ixodes festai. 


\section{REFERENCES}

ARTHur D.R. Two North African Ixodes Ticks: I. kaiseri sp. nov. from Egyptian Desert Fox Cubs. A redescription of the female and a description of the male of I. festai Rondelli, 1926 (Ixodoidea, Ixodidae). The Journal of Parasitology, 1957, 43, 578-585.

ARTHUR D.R. The synonymy of Ixodes festai Rondelli 1926. Parasitology, 1961, 51, 497-497.

ARTHuR D.R. Ticks of the genus Ixodes in Africa. The Athlone Press, University of London, 1965, 348 p.

Contini C. Further studies on Ixodes in Sardinia. Parassitologia, 1998, 40 (Suppl. 1), 37.

Gilot B. \& Perez C. Individualisation et caractérisation de deux Ixodes actuellement confondus : I. festai Rondelli, 1926, I. ventalloi Gil Collado, 1936 (Acarina, Ixodoidea). Revue Suisse de Zoologie, 1978, 85, 143-149.

Iori A., Di Giulio A. \& De Felici S. Ixodes festai TonelliRondelli, 1926: new records from Italy, and comparative morphology of females of I. festai and Ixodes ventallo $i$ Gil Collado, 1936 by SEM images. Parassitologia, 2004, 46 (Suppl. 1), 134.

Manilla G. Acari Ixodida. Fauna d'Italia, vol. 36. Calderini, Bologna, 1998, 280 p.

Papadopulos B., Humair P.F., Aeschlimann A., Vaucher C. \& BütTikeR W. Ticks on birds in Switzerland. Acarologia, 2001, 42 (1), 3-19.

PÉrez-EID C. Les tiques. Identification, biologie, importance médicale et vétérinaire. TEC \& DOC Lavoisier, Paris, 2007, 314 p.

SIUDA K., MajszYK A. \& NowAK M. Ticks (Acari: Ixodida) parasitizing birds (Aves) in Poland. Biological Letters, 2006, 43 (2), 147-151.

SiUda K. \& SZYMañski S. A case of transfer to Poland a Mediterranean tick Ixodes (Ixodes) festai Rondelli, 1926 (Acari: Ixodida: Ixodidae) by migratory birds. Wiadomsości parazytologiczne, 1991, 37, 25-29 (in Polish).

STARKOFF O. Ixodoidea d'Italia, studio monografico. Il pensiero scientifico, Roma, 1958, 385 p.

Received on January $11^{\text {th }}, 2011$ Accepted on April 20 ${ }^{\text {th }}, 2011$ 